\title{
Opinion of Healthcare Professionals in the Usage of Social Media for Patient Care in Majmaah, Saudi Arabia
}

\author{
Syed Meraj Ahmed ${ }^{1}$, Faisal Alhumaidi Alruways ${ }^{2}$, Thamer Fahad Alsallum ${ }^{3}$, \\ Meshal Munahi Almutairi ${ }^{4}$, Abdullah Saif Al-Subhi ${ }^{5}$, Ahmed Abdulaziz Ababdulkarim ${ }^{6}$ \\ ${ }^{1}$ Department of Community Medicine, College of Medicine, Majmaah University, Saudi Arabia \\ 2,3,4,5,6 College of Medicine, Majmaah University, Saudi Arabia
}

\section{Article Info}

Article history:

Received Oct 30, 2016

Revised Dec 29, 2017

Accepted Jan 12, 2017

\section{Keyword:}

Social Media

Healthcare

Patient Care

Clinicians

Saudi Arabia

\begin{abstract}
Use of social media for patient care is the new frontier in the healthcare indus-try. Sharing of information between the clinicians and their patients is now so much easier. In slowly gaining a foothold worldwide it needs a healthy push to make it universally accepta-ble. Study the knowledge, attitude, and practices of healthcare providers on the usage of social media in their clinical practice. A baseline cross - sectional study was conducted among 200 healthcare professionals from March 2015 to September 2015 on their knowledge, attitude, and practices in the use of social media for patient care in Majmaah, Saudi Arabia. A close ended self - administered validated questionnaire was used to gather data which was analyzed by using the SPSS ver. 21.0 software. $55.3 \%$ participants used social media for both professional and personal reasons. Some $(25.3 \%)$ specified using it for patient care while a significant majority $(52.9 \%)$ opined that it can be successfully used for patient interaction. Nearly 55\% agreed that social media should not be banned due to its benefits as an efficient tool for patient communication. Social media use for pa-tient doctor interaction should be encouraged to improve patient care through effective com-munication.
\end{abstract}

Copyright $\odot 2017$ Institute of Advanced Engineering and Science. All rights reserved.

\section{Corresponding Author:}

Syed Meraj Ahmed,

Department of Community Medicine,

College of Medicine,

Majmaah University, Majmaah, Saudi Arabia 11952.

Email: s.meraj@mu.edu.sa

\section{INTRODUCTION}

The healthcare industry is all about how cost effective the services is going to be and in the coming years this will take shape or already have in terms of a paperless, byte based social media platform [1],[2]. This has been possible through the immense popularity and availability of social networking sites catering to personal as well as social information and connections throughout the world [3]. A comprehensive search online indicates the enormous influence of the social media in the healthcare industry so much that the gradual changeover to a paper-less application of all the healthcare related activities has resulted in a reduction of dependence on paperwork and in the delivery of any information that needs to be sent across immediately without any unnecessary expenditure of resources [4]-[6].

Globally, as most of the healthcare organizations are incorporating the use of social media it is felt that there is a growing need to develop policies and programs to educate their employees and the consumers about its use for their mutual benefit [7],[8]. Many previous articles have pointed out the advantages of using social media by patients like helping them to overcome their fear and lack of knowledge about health and disease, browse healthcare institutions thus encouraging them to ap-proach solutions in a more practical manner [9]-[11]. Other studies have also shown improvement in patient care either during the treatment or follow up using social media that keeps the patient informed or updated regarding their progress [12]-[14]. 
Such is the effect of the increasing trend of people logging onto social networking site to gather healthcare information or connecting with their healthcare providers that several articles have concluded it is inevitable for newer software engaging pa-tients with their clinicians during recovery period and beyond to become popular [15],[16]. Very few literatures are available in Saudi Arabia regarding its effectiveness among which some have pointed out the lack of trust among users in such means of information which are counter checked from other sources of information too [17],[18]. Brian S et al concluded that the clinicians primarily used it to share information between colleagues or to learn new information in the field of medicine while some suggested that clinicians can suggest appropriate online apps for the patient to ob-serve the progress of their treatment and cure via positive feedback from their healthcare provider [19],[20]. James Brown et al [21] did a survey among doctors in Australia and found that less than 48\% shared information online with their patient (when requested) even though majority (> 70\%) of them accessed some social media website online. This suggested that availability of the social media requires proper utilization for greater benefits in clinical practice.

In 2009 the Center for Disease Control and prevention (CDC) has used Twitter during H1N1 pandemic to increase awareness among users by creating twitter ac-count for emergency information which attracted more than 1.5 Million followers [22],[23]. The CDC found that this account was faster helpful and powerful for health promotion [24]. In KSA, the Ministry of Health used their own Twitter account to post an information about health education and promotion, and the number of followers exceeded 744,000. A study by Tilburg University, Netherlands addressed patient issues like privacy concern and information reliability in the use of social media and health professional's concerns regarding inefficiency and lack of skills in using the social media [25].

Since very few information is available about use of social media by healthcare pro-fessionals in Saudi Arabia in general and Majmaah in particular, a need was felt to develop a baseline study on perception and practice of healthcare providers regard-ing its use in their interaction with patients and peers alike.

General objective:

- To study the knowledge, attitude and practices of healthcare providers on the usage of social media in their clinical practice.

Specific objectives:

- To assess the level of awareness about social media among healthcare per-sonnel

- To study the attitude of healthcare personnel towards usage of social media for care and follow up of patients

- To compare the frequency of use of social media by clinicians for personal use in relation to its use for professional purpose.

- To identify the barriers to the use of social media in clinical care from the health professionals point of view.

\section{RESEARCH METHOD}

This was a cross - sectional interview based study among healthcare professionals to find out their knowledge, attitude, and practice in utilizing the social media for the treatment and care of patients. This study was conducted among the qualified healthcare providers working in the government and private hospitals, primary health care centers, Dental clinics, Medical colleges and self-managed clinics in Majmaah city, KSA. For sampling a complete enumeration method was used to include all the qualified healthcare professionals in Majmaah for data collection.

The data collection from the above sample took around 6 months to be completed as planned. A pretested, preformed interviewee based and close ended questionnaire was used to collect data from the study participants. The data was entered by the study participants in the presence of the field investigator with prior appointment during his free time from clinical work in his workplace. Any query raised during the time was answered to the satisfaction of the participants. A reappointment was taken from participants who were not available during the given time so that the desired sample size calculated was reached.

All the data was entered in the SPSS software and statistical analysis done. Statistical tests like modified Pearson's Chi square tests and analysis of variance was used to find out the significance of the knowledge, attitude and practice of healthcare providers in the use of social media for patient care. A $95 \%$ degree of freedom with p-value of $<0.05$ would be considered as statistically significant.

\subsection{Ethical Considerations}

Participation consent from the physician was taken after they were thoroughly briefed about the aim and objective of the study and the advantage to them as well as to the community due to the impact of this 
study. They were assured that all the information would be kept purely confidential and will only be used for statistical analysis.

\subsection{Inclusion and exclusion criteria}

All the physician/specialists who are working or residing in Majmaah city were in-cluded in the study. Any study participants who voluntarily refused to participate in the study and physicians practicing alternative medicine were excluded.

\section{RESULTS AND ANALYSIS}

A total of 170 participants responded to the questionnaire. This was around $85 \%$ of the target population to whom the invitation to participate was sent.

Majority of the participants $(47.1 \%)$ were aged between 30 - 40 years while quite a few were more than 45 years old $(27.06 \%)$ as shown in Figure 1. The percentage of non - Saudi participants (87.6\%) was more than those of Saudi origin $(12.4 \%)$ as shown in Table 1.

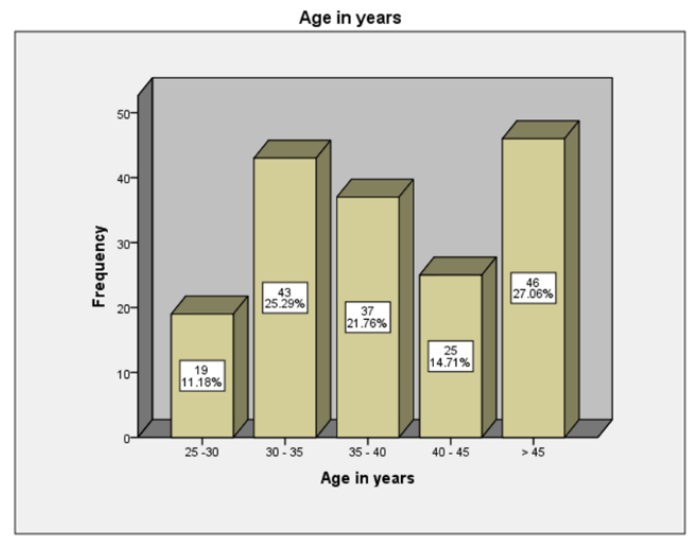

Figure 1. Age distribution of the study participants

Table 1. Distribution of The Participants According to The Nationality

\begin{tabular}{clccc}
\hline & & Frequency & Percent & Valid Percent \\
\hline Valid & Saudi & 21 & 12.4 & 12.4 \\
& Non-Saudi & 149 & 87.6 & 87.6 \\
& Total & 170 & 100.0 & 100.0 \\
\hline
\end{tabular}

Females made up around $28 \%$ of the total population as shown in Figure 2. Participants from King Khaled Hospital (49.4\%) formed most the study population followed by those from College of Medicine, Majmaah $(28.2 \%)$ can be seen in Table 2.

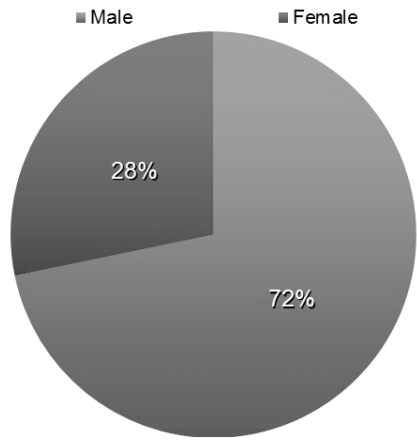

Figure 2. Distribution of Study Participants According To Gender 
Table 2. Distribution of The Participants According to The Workplace

\begin{tabular}{clccc}
\hline & Frequency & Percent & Valid Percent \\
\hline Valid & Hospital & 84 & 49.4 & 49.4 \\
& Medical College & 48 & 28.2 & 28.2 \\
& Dental Hospital & 7 & 4.1 & 4.1 \\
Clinics & 31 & 18.2 & 18.2 \\
& Total & 170 & 100.0 & 100.0 \\
\hline
\end{tabular}

Most of the study participants agreed on using the social media $(89.4 \%)$ out of which $75 \%$ were from the clinical specialty though it was not statistically significant $(\mathrm{p}=0.577)$ as shown in Table 3 .

Table 3. Comparison of Social Media Usage with Specialty

\begin{tabular}{|c|c|c|c|c|c|}
\hline & & \multicolumn{3}{|c|}{ Specialty } & \multirow{2}{*}{ Total } \\
\hline & & Preclinical & Para clinical & Clinical & \\
\hline Do you use the social & Yes $(\%)$ & $22(14.5)$ & $16(10.5)$ & $114(75.0)$ & $152(89.4)$ \\
\hline media (twitter, FB etc.) & No $(\%)$ & $1(5.6)$ & $2(11.1)$ & $15(83.3)$ & $18(10.6)$ \\
\hline Total & & $23(13.5)$ & $18(10.6)$ & $129(75.9)$ & $170(100.0)$ \\
\hline
\end{tabular}

Pearson's $\chi 2=1.099, \mathrm{p}=0.577, \mathrm{df}=2$ (not significant)

Many of the participants agreed on using the social media for both personal and professional purpose $(55.3 \%)$ and another $28.8 \%$ preferred to use it more for per-sonal purpose. Surprisingly, very few $(5.3 \%)$ were using it as an official tool for pa-tient care as shown in Table 4.

Table 4. Frequency of Use of Social Media by The Study Participants

\begin{tabular}{llccc}
\hline & Frequency & Percent & Valid Percent \\
\hline Valid & Mostly personal & 49 & 28.8 & 28.8 \\
& Mostly official & 9 & 5.3 & 5.3 \\
& Official and personal & 94 & 55.3 & 55.3 \\
& Not response & 18 & 10.6 & 10.6 \\
& Total & 170 & 100.0 & 100.0 \\
\hline
\end{tabular}

This survey showed a positive attitude among study participants as shown in Table 5, a sig-nificant majority of who $(52.9 \%)$ opined that social media can be successfully used as a tool for patient care as compared to $22.9 \%$ who disagreed $(\mathrm{p}<0.05)$.

Table 5. Opinion of Study Participants on The Usage of Social Media for Patient Care

\begin{tabular}{lcccccc}
\hline \multirow{2}{*}{ Workplace } & \multicolumn{2}{c}{ Social media use can improve the quality of clinical care of patients } & \multirow{2}{*}{ Total } \\
& Strongly agree & Agree & Neutral & Disagree & Strongly disagree & \\
\hline Hospital & $15(17.9)$ & $26(31.0)$ & $18(21.4)$ & $14(16.7)$ & $11(13.1)$ & $84(100.0)$ \\
Medical College & $6(12.5)$ & $16(33.3)$ & $14(29.2)$ & $8(16.7)$ & $4(8.3)$ & $48(100.0)$ \\
Dental Hospital & $0(0.0)$ & $2(28.6)$ & $5(71.4)$ & $0(0.0)$ & $0(0.0)$ & $7(100.0)$ \\
Clinics & $7(22.6)$ & $18(58.1)$ & $4(12.9)$ & $1(3.2)$ & $1(3.2)$ & $31(100.0)$ \\
Total & $28(16.5)$ & $62(36.5)$ & $41(24.1)$ & $23(13.5)$ & $16(9.4)$ & $170(100.0)$ \\
\hline
\end{tabular}

Pearson's $\chi^{2}=23.729, \mathrm{p}=0.022, \mathrm{df}=12$ (Significant)

It is interesting to observe that a significant number of participants $(54.7 \%)(\mathrm{p}<0.05)$ were using the social media primarily at home as compared to in both home and of-fice (32.9\%) as shown in Table 6.

Table 6. Distribution of The Place of Use of Social Media

\begin{tabular}{|c|c|c|c|c|c|}
\hline \multirow{2}{*}{ Workplace } & \multicolumn{4}{|c|}{ Where Do you use it more often? } & \multirow{2}{*}{ Total } \\
\hline & At Home, mostly & At office, Mostly & Both home and office & No response & \\
\hline Hospital & $56(66.7)$ & $1(1.2)$ & $20(23.8)$ & $7(8.3)$ & $84(100.0)$ \\
\hline Medical College & $22(45.8)$ & $0(0.0)$ & $24(50.0)$ & $2(4.2)$ & $48(100.0)$ \\
\hline Dental Hospital & $3(42.9)$ & $1(14.3)$ & $2(28.6)$ & $1(14.30$ & $7(100.0)$ \\
\hline Clinics & $12(38.7)$ & $1(.2)$ & $10(32.3)$ & $8(25.8)$ & $31(100.0)$ \\
\hline Total & $93(54.7)$ & $3(1.8)$ & $56(32.9)$ & $18(10.6)$ & $170(100.0)$ \\
\hline
\end{tabular}

Pearson's $\chi 2=27.67, \mathrm{p}=0.001, \mathrm{df}=9$ (Significant)

IJPHS Vol. 6, No. 1, March 2017: $13-20$ 
As far as using the social media primarily for patient care is concerned, the re-sponse was around $25 \%$ who said they do while more than $75 \%$ answered in the negative, it can be seen in Table 7 .

Table 7. Distribution of Participants in Touch with Patients through Social Media

\begin{tabular}{lccc}
\hline & Frequency & Percent & Valid Percent \\
\hline Yes & 43 & 25.3 & 25.3 \\
No & 117 & 68.8 & 68.8 \\
Don't Know & 10 & 5.9 & 5.9 \\
Total & 170 & 100.0 & 100.0 \\
\hline
\end{tabular}

The survey did though reveal that the physicians have a positive attitude towards use of electronic media like social websites to interact with patients (Table 8). A significant $(\mathrm{p}<0.05)$ majority $(50.6 \%)$ didn’t agree with banning the social media as a tool for patient care.

Table 8. Opinion on Banning Social Media as a Tool for Practicing Healthcare

\begin{tabular}{lcccc}
\hline \multirow{2}{*}{ Workplace } & \multicolumn{2}{c}{ Do you think that the social media should be } & Total \\
& banned as a tool for practicing health care & Don't Know & \\
\hline Hospital & $31(36.9)$ & $43(51.2)$ & $10(11.9)$ & $84(100.0)$ \\
Medical College & $10(20.8)$ & $27(56.3)$ & $11(22.9)$ & $48(100.0)$ \\
Dental Hospital & $1(14.3)$ & $4(57.1)$ & $2(28.6)$ & $7(100.0)$ \\
Clinics & $17(54.8)$ & $12(38.7)$ & $2(6.5)$ & $31(100.0)$ \\
Total & $59(34.7)$ & $86(50.6)$ & $25(14.7)$ & $17000.0)$ \\
\hline
\end{tabular}

\subsection{Discussion}

Multiple studies worldwide have shown a positive correlation of patient care with usage of the social media by the healthcare professionals [26]-[28]. Our study has tried to analyze the knowledge, attitude and practice of the healthcare professionals to-wards this social media and its advantages in patient care. It was seen that most of the healthcare professionals are on social media $(89.4 \%)$ but very few had direct interactions with the patients through this method (25.3\%). Similarly, other articles [29],[30] have also pointed out that patients have tried to connect with their physicians via social media than the other way around. In other similar study in Australia, 187 doctors, three-quarters of them used social media, only $30.5 \%$ had communicated with a patient through email and $(48.1 \%)$ could offer their patients electronic forms of information if that were the patients' preference [31].

We have seen that lately apart from the direct face to face communication among doctors and patients the popularity of the online interaction has increased expo-nentially but somewhere has been hindered by the delay in the attitudinal change among physicians. Our study showed that almost $23.0 \%$ of the participants disa-greed about using the social media for patient care. Other articles [32]-[34] have also rightly pointed out to this disparity and cited it as a hindrance to the improvement in patient care services.

This study has shown that there has been an optimistic response $(50.6 \%)$ from the healthcare professionals for not banning the social media use for patient care. Mul-tiple articles [35]-[38] have shared this view with a futuristic vision of a world where an-yone anywhere can have easy and timely access to the best physicians at a very personal level for their treatment and care.

\section{CONCLUSION}

This study is attempts to prove that the usage of social media in general and for pa-tient care by the healthcare professional is beneficial in the long run. The survey done in this study provides ample information regarding the positive attitude of the study participants. Moreover, there is an expectation that with enough support from the management and the government the use of social media will greatly benefit the patients both in their treatment and follow up. In fact, most of the previous studies have echoed similar outcomes in terms of patient care and ease of communica-tion with their clinicians from the comfort of their homes.

\section{RECOMMENDATION}

A pilot attempt of our paper to establish a baseline study to assess the knowledge, attitude and practices of the healthcare professionals from different field of exper-tise have shown motivating results.

Opinion of Healthcare Professionals in the Usage of Social Media for Patient .... (Syed Meraj Ahmed) 
Primarily certain gaps need to be filled like in-creasing the usage of social media for patient care in hospital and healthcare set-tings. Regular training is required for the healthcare professionals to have a better grasp of the use of social media for patient treatment and follow up. A health educa-tion and awareness campaign by the central government to the general population and the healthcare fraternity to take the healthcare services to the next level of intervention.

\section{LIMITATIONS}

This was a self-questionnaire based study and respondent bias cannot be ruled out. This could impact the result of the study in some way though attempts were made to explain to the participants on how to approach answering the question-naire. Furthermore, due to time constraint more number of participants could not be included in the study sample. A modified Chi square test (Fisher's Exact) was used for analysis since the sample size was smaller and this could affect the projection of the study result to the population. Since this was an attempt to establish a baseline study in Majmaah on a very trending topic worldwide, efforts should be made to overcome these limitations in future studies.

\section{ACKNOWLEDGEMENTS}

A kind appreciation to the Department of Community Medicine, College of Medicine for the successful conduct of this study within the given time frame.

\section{REFERENCES}

[1] S. Kahn J., "The wisdom of patients: health care meets online social media," 2008.

[2] http://www.whatissocialnetworking.com/ (Accessed on 15.12.2014)

[3] http://www.mediabistro.com/alltwitter/social-networking-ages_b58149.

[4] http://www.huffingtonpost.com/vala-afshar/the-power-of-social-media_b_4853773.html

[5] http://www.imshealth.com/portal/site/imshealth/menuitem.762a961826aad98f53c753c71 ad8c22a/?vgnextoid=ff71a d0087c73410VgnVCM10000076192ca2RCRD\&vgnextchannel=a64de5fda6370410VgnVCM10000076192ca2RC $\mathrm{RD}$

[6] http://www.informationweek.com/healthcare/clinical-information-systems/will-social-media-revolutionizehealthcare/a/d-id/1315893

[7] http://www.nortecehr.com/. Accessed on 02.12.2014

[8] http://www.csc.com/health_services/insights/80626-healthcare_social_media_integration. Accessed on 02.12.2014

[9] Boyer C., "Social media for healthcare makes sense. Front Health Serv Manage," Winter, vol/issue: 28(2), pp. 3540, 2011.

[10] Sarringhaus M. M., “The great divide: Social media's role in bridging healthcare's generational shift," Journal of Healthcare Management, vol/issue: 56(4), pp. 235-44, 2011.

[11] Leman H., "Social media in healthcare: Connect, communicate, and collaborate," Journal of the Medical Library Association, vol/issue: 100(2), pp. 148-9, 2012.

[12] D. Queen and K. Harding, "Social Media Can Revolutionise Health Care Provider-Patient Relationship," International Wound Journal, vol. 11, pp. 109, 2014.

[13] O. D. Gubler N., "Using social media to improve patient care and outcomes," Optometry Times, vol/issue: 5(6), pp. 28, 28, 30, 2013.

[14] Book Section, "Social Media in Clinical Practice, Use of Social Media by Hospitals and Medical Practices," Springer London, A Meskó, Bertalan, pp. 109-114.

[15] Timimi F. K., "Medicine, morality and health care social media," BMC Medicine, vol. 10, pp. 83, 2012.

[16] Hackworth B. A. and Kunz M. B., "Health Care and Social Media: Bulding Relationships via Social Networks," Academy of Health Care Management Journal, vol/issue: 7(2), pp. 1-14, 2011.

[17] ALrukban A., "The health related uses of social media among users in Saudi Arabia," Int J Med Sci Public Health, 2014.

[18] M. Househ, et al., "Empowering patients through social media: The benefits and challenges," Health Informatics Journal, vol/issue: 20(1), pp. 50-58, 2014.

[19] McGowan B. S., et al., "Understanding the Factors That Influence the Adoption and Meaningful Use of Social Media by Physicians to Share Medical Information,” J Med Internet Res, vol/issue: 14(5), pp. e117, 2012.

[20] Edwin D. B., et al., "Evaluating and selecting mobile health apps: strategies for healthcare providers and healthcare organizations," Translational Medicine, 2014.

[21] Brown J., et al., "How Doctors View and Use Social Media: A National Survey," J Med Internet Res, vol/issue: 16(12), pp. e267, 2014.

[22] Eytan T., et al., "Social media and the health system," Perm J., vol/issue: 15(1), pp. 71-4, 2011.

[23] Chew C. and Eysenbach G., "Pandemics in the age of Twitter: content analysis of Tweets during the 2009 H1N1 outbreak," PLoS One, vol/issue: 5(11), pp. e14118, 2010. 
[24] Merchant R. M., et al., "Integrating social media into emergency-preparedness efforts," $N$ Engl J Med, vol/issue: 365(4), pp. 289- 91, 2011.

[25] http://www.ncbi.nlm.nih.gov/pubmed/23899831. (Accessed on 12.01.2015)

[26] Hawn C., "Take two aspirin and tweet me in the morning: how Twitter, Facebook, and other social media are reshaping health care," Health Aff (Millwood), vol/issue: 28, pp. 361-8, 2009.

[27] D. McCaughey, et al., "Best Practices in Social Media Utilizing a Value Matrix to Assess Social Media's Impact on Health Care," Social Science Computer Review, vol/issue: 32(5), pp. 575-589, 2014.

[28] W. Kim and R. Vender, "Use of Facebook as a Tool for Knowledge Dissemination in Dermatology; Canadian Dermatology Association," Journal of Cutaneous Medicine and Surgery, vol/issue: 18(5), pp. 341-344, 2014.

[29] M. von Muhlen and L. O. Machado, "Reviewing social media use by clinicians, Journal of the American Medical Informatics Association, vol/issue: 19(5), pp. 777-781, 2012.

[30] G. T. Bosslet, et al., "The Patient-Doctor Relationship and Online Social Networks: Results of a National Survey," Journal of General Internal Medicine, vol/issue: 26(10), pp. 1168-1174, 2011.

[31] http://www.ncbi.nlm.nih.gov/pmc/articles/PMC4275505//e267; Accessed on 15.05.2015.

[32] F. K. Timimi, "Medicine, morality and health care social media," BMC Medicine, vol. 10, pp. 83, 2012.

[33] DeCamp M., "Ethics and the Physician-Patient Relationship: Medico-moral Consequences of Commodification," Einstein Quart J Biol Med, vol. 19, pp. 135-138, 2002.

[34] R. Shore, et al., "Report of the AMA Council on Ethical and Judicial Affairs: professionalism in the use of social media," The Journal of clinical ethics, vol/issue: 22(2), pp. 165-172, 2010.

[35] C. B. Thielst, "Social Media in Healthcare," Chicago, Health Administration Press, 2010).

[36] W. Y. S. Chou, et al., "Social media use in the United States: implications for health communication," Journal of medical Internet research, vol/issue: 11(4), 2009.

[37] M. Terry, "Twittering healthcare: social media and medicine," Telemedicine and e-Health, vol/issue: 15(6), pp. 507-510, 2009.

[38] K. L. Courtney, "The use of social media in healthcare: organizational, clinical, and patient perspectives," Enabling Health and Healthcare Through ICT: Available, Tailored and Closer, pp. 183, 244, 2013.

\section{BIOGRAPHIES OF AUTHORS}

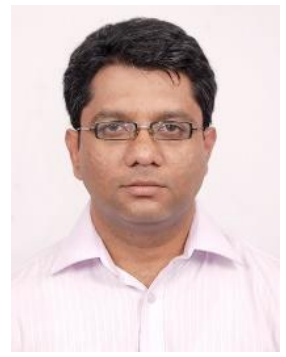

Dr. Syed Meraj Ahmed (MBBS, MD, MPH, IPHA)

Associate Professor

Department of Community Medicine

College of Medicine,

Majmaah University

Majmaah - 11952

Saudi Arabia

Mobile: +966552194531

Email: s.meraj@mu.edu.sa/ merajahmed10@ hotmail.com

Faisal Alhumaidi Alruways

Final Year MBBS student

College of Medicine

Majmaah University,

Majmaah - 11952

Saudi Arabia

Email: falruways@gmail.com

Thamer Fahad A Sallum

Final Year MBBS student

College of Medicine

Majmaah University,

Majmaah - 11952

Saudi Arabia

Email: thamer.v2@gmail.com

Meshal Munahi D Almutairi

Final Year MBBS student

College of Medicine

Majmaah University,

Majmaah - 11952

Saudi Arabia

Email: meshal_alduwaifry@hotmail.com 
Abdullah Saifaldeen Alsubhi

Final Year MBBS student

College of Medicine

Majmaah University,

Majmaah - 11952

Saudi Arabia

Email: a.s_al-subhi@hotmail.com

Ahmed Abdulaziz Alabdulkarim

Final Year MBBS student

College of Medicine

Majmaah University,

Majmaah - 11952

Saudi Arabia

Email: rbr917@hotmail.com 